\title{
FAKTOR-FAKTOR YANG MEMPENGARUHI BELAJAR TERHADAP PRESTASI SISWA PADA MATA PELAJARAN MATEMATIKA DENGANMENGGUNAKANANALISIS JALUR (Studi Kasus : SMK Negeri 1 Siborongborong)
}

\author{
Mariana Simanjuntak, Hamidah Nasution \\ Jurusan Matematika FMIPA, UNIMED, Medan, Indonesia \\ e-mail: Marianasimanjuntak90@gmail.com
}

\begin{abstract}
This study aims to determine the factors that affect learning in SMK Negeri 1 Siborongborong with test and seek the path coefficient correlation coefficient, determine the causal relationship between exogenous and endogenous variables determine the factors that most influence on student achievement. To answer these objectives researchers using Path Analysis. The data used in this study are primary data and secondary data, where the data obtained from the questionnaires filled by the respondent and then the data is processed using Path Analysis with SPSS 16.0 for windows. The results showed bahwafaktor most influence on student achievement is a great method of learning with the influence of 0,261 and a significant relationship between the factors studied were composed of variations of teachers teaching, interest in learning, learning methods, intelligence and motivation of students studying on student achievement.
\end{abstract}

Keywords: Path Analysis, variation teachers teach, interest in learning, learning methods, learning motivation, intelligence of students.

\section{Pendahulua}

\section{Latar Belakang}

Matematika merupakan Queen and servant of science (ratu dan pelayan ilmu pengetahuan). Matematika dikatakan sebagai ratu karena pada perkembangannya tidak tergantung pada ilmu lain serta banyak ilmu-ilmu yang penemuannya bersumber dari 
matematika. Selain itu matematika juga bisa melatih untuk senantiasa berpikir logis dan kritis dalam memecahkan permasalahan. Selain itu, kejujuran, ketekunan dan keuletan juga akan terlatih dengan matematika.

Matematika bagi sebagian besar siswa adalah mata pelajaran yang tidak disukai bahkan dibenci. Hasil survei sederhana yang dilakukan peneliti setiap awal tahun, jika ada pertanyaan mata pelajaran apa yang disukai siswa, maka jawabannya hampir $90 \%$ siswa menjawab selain mata pelajaran matematika. Sebaliknya jika ditanya mata pelajaran apa yang tidak disukai, maka hampir $75 \%$ menjawab matematika [1]. Berbagai macam cara digunakan baik oleh sekolah maupun guru-guru dengan harapan dapat meningkatkan prestasi belajar matematika. Usaha-usaha tersebut antara lain dengan jam tambahan kelas XI, dan bahkan guru-guru mengadakan kegiatan kelompok mengajar atau sering disebut dengan "team teaching". Pada kegiatan tersebut satu kelas diajar oleh dua orang guru dimana satu guru menjadi guru model (mengajar di depan kelas) dan satu orang guru menjadi observer. Namun demikian ternyata hasilnya belum optimal, ini ditunjukan dengan prestasi siswa yang masih rendah [2].

Adapun faktor-faktor belajar yang dapat mempengaruhi prestasi siswa yang akan dibahas oleh penulis adalah sebagai berikut:

1. Variasi gaya mengajar guru

2. Minat belajar

3. Metode belajar

4. Inteligensi siswa

5. Motivasi belajar

Analisis jalur merupakan suatu teknik analisis statistika yang dikembangkan dari analisis regresi berganda.Dalam model regresi, model yang terbentuk digunakan untuk meramalkan (memprediksi) variabel endogen (variabel terikat) apabila variabel eksogen (variabel bebas) diketahui. .Sedangkan dalam analisis jalur, model yang terbentuk digunakan untuk menjelaskan besarnya pengaruh (bukan memprediksi) variabel eksogen (variabel bebas) terhadap variabel endogen (variabel terikat).Dalam analisis jalur terdapat dua metode analisis, yaitu metode dekomposisi dan metode trimming.

Apabila tujuan penelitian adalah membentuk model kausal yang memasukkan seluruh variabel yang diamati maka digunakan metode dekomposisi. Sedangkan metode trimming digunakan untuk memperbaiki suatu model struktur analisis jalur dengan cara mengeluarkan variabel eksogen yang koefisien jalurnya tidak signifikan [3]. 
Teknik analisis yang dapat digunakan untuk mengetahui hubungan antar variabel tersebut adalah Analisis Jalur model Trimming. Analisis jalur adalah suatu teknik untuk meng-analisis hubungan sebab akibat yang terjadi pada regresi berganda jika variabel eksogennya mempengaruhi variabel endogen tidak hanya secara langsung, tetapi juga secara tidak langsung $[4,5]$.

Tulisan ini membahas hubungan satu variabel dengan variabel lain menggunakan Analisis Jalur (path analysis) untuk membahas hubungan antara usia ibu, kadar hemoglobin, dan masa gestasi terhadap berat bayi lahir di Rumah Sakit Aisyiyah Kudus. Berdasarkan hasil pembahasannya, diperoleh kesimpulan bahwa variabel yang paling dominan berpengaruh terhadap berat bayi yaitu masa gestasi, dimana besar pengaruh langsung sebesar -0.70903 sedangkan untuk pengaruh tidak langsung sebesar 0.1626 .

\section{Metode Penelitian}

Penelitian ini dilakukan di Lembaga pendidikan SMK Negeri 1 Siborongborong yang berlokasi di Jl. Balige Km 2,2 Siborongborong, Kabupaten Tapanuli Utara dan waktu penelitian dilakukan selama kurang lebih satu bulan.

\section{Teknik Pengumpulan Data}

Data yang digunakan dalam penelitian ini adalah :

Data primer, yaitu data yang diperoleh langsung dari sumbernya, diamati dan dicatat untuk pertama kalinya. Dalam penelitian ini, data primer yang dimaksud adalah data yang diperoleh dari kuesioner yang ditanyakan langsung kepada Siswa-siswi SMK Negeri 1 Siborongborong.

Data sekunder, yaitu data yang diperoleh misalnya dari biro statistik, majalah, keterangan-keterangan atau publikasi lainnya. Dalam penelitian ini, data sekunder yang dimaksud yaitu dokumen Siswa-siswi SMK Negeri 1 Siborongborong.

\section{Teknik Pengambilan Sampel}

Populasi yang digunakan dalam penelitian ini adalah dari Siswa-siswi SMK Negeri 1 Siborongborongberjumlah 800 orang. Teknik pengambilan sampel menggunakan rumus Slovin, yaitu : 


$$
n=\frac{N}{1+N e^{2}}
$$

Dimana, $n$ adalah Jumlah sampel, $N$ adalah Jumlah populasi dan $e$ adalah Taraf kesalahan (10\%).

Untuk $N=800$ dan $e=10 \%$ maka: $n=\frac{N}{1+N e^{2}}$ $n=\frac{800}{1+800(0.1)^{2}}=80$ Orang

Berdasarkan rumus Slovin tersebut, peneliti menetapkan sampel sebanyak 80 orang dengan taraf kesalahan $10 \%$.

\section{Prosedur Penelitian}

Prosedur penelitian yang dilakukan adalah :

1. Pengumpulan Data

Beberapa data yang harus dikumpulkan sebelum melakukan pengolahan data, yaitu:

a. Data primer, yaitu data yang diperoleh langsung dari sumbernya, diamati dan dicatat untuk pertama kalinya. Dalam penelitian ini, data primer yang dimaksud adalah data yang diperoleh dari kuesioner yang ditanyakan langsung kepada Siswa-siswi SMK Negeri 1 Siborongborong.

b. Data sekunder, yaitu data yang diperoleh misalnya nilai rapor, keterangan-keterangan atau publikasi lainnya. Dalam penelitian ini, data sekunder yang dimaksud yaitu dokumen Siswa-siswi SMK Negeri 1 Siborongborong.

2. Pengolahan Data Menggunakan Analisis Jalur

Tahap Analisis Jalur digunakan untuk menganalisis faktor-faktor yang mempengaruhi belajar terhadap prestasi siswa. Hasil kuisioner merupakan data atau informasi yang akan dipergunakan untuk mengetahui besarnya pengaruh langsung maupun tidak langsung dengan Analisis Jalur. Pengolahan data menggunakan Analisis Jalur dengan menggunakan program SPSS.

\section{Pembahasan Dan Hasil}

\section{Variabel Penelitian}

Adapun variabel dalam peneltian ini adalah :

Variabel bebas $X$ dimana variabel bebasnya terdiri dari :

a. Variabel $X_{1}$ yaitu variasi gaya mengajar guru 
b. Variabel $X_{2}$ yaitu minat belajar siswa

c. Variabel $X_{3}$ yaitu metode belajar

d. Variabel $X_{4}$ yaitu inteligensi siswa

e. Variabel $X_{5}$ yaitu motivasi belajar

f. Variabel terikat $Y$ yaitu prestasi siswa pada pelajaran matematika .

g.

Tabel 1. Variabel Operasional

\begin{tabular}{|c|c|}
\hline Variabel & Indikator \\
\hline \multirow{4}{*}{ Variasi gaya mengajar guru } & Pemanfaatan waktu \\
\hline & Komunikasi antara siswa dan guru \\
\hline & Intonasi Suara \\
\hline & Model Pembelajaran \\
\hline \multirow{4}{*}{ Minat belajar siswa } & Menguasai materi \\
\hline & Mengulang materi \\
\hline & Memanfaatkan waktu luang \\
\hline & Sistem belajar \\
\hline \multirow{4}{*}{ Metode belajar } & Optimis \\
\hline & Memanfaatkan waktu luang \\
\hline & Merasa tertantang \\
\hline & Semangat yang kuat \\
\hline \multirow{3}{*}{ Inteligensi siswa } & Komunikasi yang baik dengan guru \\
\hline & $\begin{array}{l}\text { Komunikasi yang baik dengan sesama } \\
\text { siswa }\end{array}$ \\
\hline & Ide yang bagus \\
\hline \multirow{4}{*}{ Motivasi belajar } & Cara belajar \\
\hline & Optimis \\
\hline & Semangat yang tinggi \\
\hline & Dorongan dari lingkungan \\
\hline Prestasi siswa & Nilai \\
\hline
\end{tabular}

\section{Deskriptif Responden}


Metode ini merupakan suatu metode analisis dimana data yang dikumpulkan pertama disusun, diklasifikasikan, dan dianalisis sehingga akan memberikan gambaran yang jelas mengenai masalah yang sedang diteliti. Analisis deskriptif dalam penelitian ini merupakan uraian atau penjelasan dari hasil pengumpulan data primer berupa kuisioner yang diisi oleh responden penelitian.Kuisioner yang digunakan dalam penelitian ini diukur dalam skala likert untuk menyatakan pengaruh factor belajar terhadap prestasi siswa SMK Negeri 1 Siborongborong.Jumlah seluruh pernyataan adalah 30 butir. Responden penelitian adalah siswa SMK Negeri 1 Siborongborong.

Tabel 2. Karakteristik Responden Berdasarkan Jenis Kelamin

\begin{tabular}{|c|c|c|}
\hline Jenis Kelamin & Frekuensi & Persentase \\
\hline Pria & 44 & $\frac{44}{80} X 100 \%=55 \%$ \\
\hline Wanita & 36 & $\frac{36}{80} X 100 \%=45 \%$ \\
\hline Jumlah & 80 & $100 \%$ \\
\hline
\end{tabular}

Jumlah siswa Pria sebanyak 44 orang atau (55\%) dan jumlah wanita sebanyak 36 orang atau $(45 \%)$.

Tabel 3. Karakteristik Responden Berdasarkan Kelas

\begin{tabular}{|c|c|c|}
\hline Tingkat Kelas & Frekuensi & Presentase \\
\hline$X$ & 43 & $\frac{43}{80} X 100 \%=53.75 \%$ \\
\hline XI & 37 & $\frac{37}{80} X 100 \%=46.25 \%$ \\
\hline Jumlah & 80 & $100 \%$ \\
\hline
\end{tabular}

Jumlah siswa pada kelas X sebanyak 43 siswa $(53,75 \%)$ sedangkan jumlah siswa pada kelas XI sebanyak 37 siswa $(46,25 \%)$.

\section{Diagram Jalur}

Data yang digunakan adalah data primer yang diperoleh melalui koesioner yang bersifat terbuka untuk setiap pertanyaan yang bersifat pribadi. Berdasarkan teori yang dipaparkan mengenai faktor-faktor yang mempengaruhi belajar terhadap prestasi siswa, maka dalam bab pembahasan ini yang berkedudukan sebagai variabel endogen adalah 
prestasi siswa $(Y)$. Variabel yang kedudukannya sebagai eksogen adalah variasi guru mengajar $\left(X_{1}\right)$, minat belajar $\left(X_{2}\right)$, metode belajar $\left(X_{3}\right)$, inteligensi siswa $\left(X_{4}\right)$ dan morivasi belajar $\left(X_{5}\right)$.

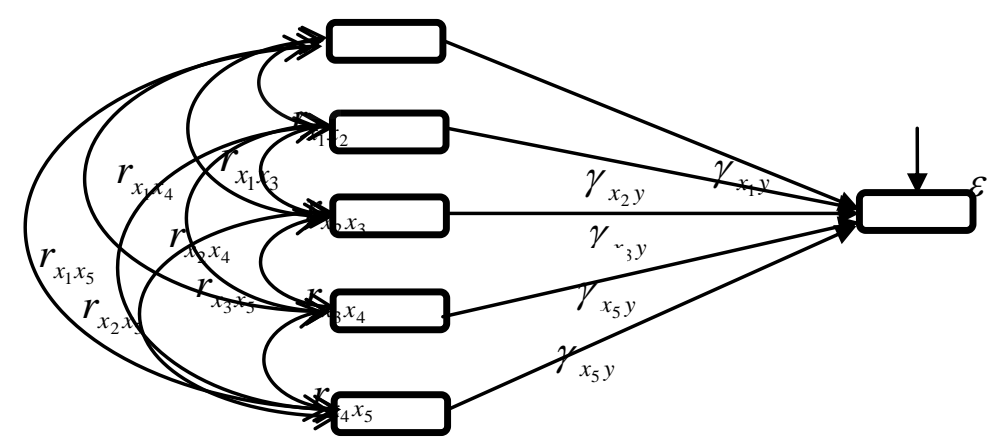

Gambar 1. Diagram Jalur

Gambar 1. diatas menyatakan bahwa hanya terdiri dari sebuah substruktur yang berisi lima buah variabel eksogen dan sebuah variabel endogen. Persamaan strukturnya diagram diatas adalah:

$Y=\gamma_{y x_{1}} X_{1}+\gamma_{y x_{2}} X_{2}+\gamma_{y x_{3}} X_{3}+\gamma_{y x_{4}} X_{4}+\gamma_{y x_{5}} X_{5}+\varepsilon$ Menghitung Korelasi Antar Variabel

Menghitung korelasi antar variabel. Nilai korelasi antar variabel dihitung dengan menggunakan rumus :

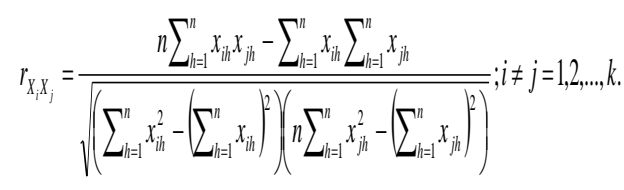

Dengan bantuan spss 16.0 diperoleh nilai korelasi antar variabel yang ditunjukkan pada tabel sebelumnya sebagai berikut:
a. $\quad X_{1}$ dan $X_{2}=0.590$
b. $\quad X_{1}$ dan $X_{3}=0.799$
c. $\quad X_{1}$ dan $X_{4}=0.766$
d. $\quad X_{1}$ dan $X_{5}=0.656$ 
e. $X_{1}$ dan $Y=0.776$

f. $\quad X_{2}$ dan $X_{3}=0.812$

g. $\quad X_{2}$ dan $X_{4}=0.758$

h. $\quad X_{2}$ dan $X_{5}=0.712$

i. $\quad X_{2}$ dan $Y=0.818$

j. $\quad X_{3}$ dan $X_{4}=0.874$

k. $\quad X_{3}$ dan $X_{5}=0.798$

1. $X_{3}$ dan $Y=0.897$

m. $X_{4}$ dan $X_{5}=0.680$

n. $\quad X_{4}$ dan $Y=0.848$

o. $\quad X_{5}$ dan $Y=0.801$

\section{Menghitung Matriks Korelasi [6].}

Menentukan matriks korelasi diperoleh berdasarkan nilai-nilai korelasi antar variabel.Berdasarkan hasil pengelolaan data yang ditunjukkan dalam tabel 4.4 maka susunan matriks korelasi antar variabel sebagai berikut:

$$
\begin{aligned}
& R_{x_{i} x_{j}}=\left[\begin{array}{ccccc}
1 & r_{x_{1} x_{2}} & r_{x_{1} x_{3}} & r_{x_{1} x_{4}} & r_{x_{1} x_{5}} \\
r_{x_{2} x_{1}} & 1 & r_{x_{2} x_{3}} & r_{x_{2} x_{4}} & r_{x_{2} x_{5}} \\
r_{x_{3} x_{1}} & r_{x_{3} x_{2}} & 1 & r_{x_{3} x_{4}} & r_{x_{3} x_{5}} \\
r_{x_{4} x_{1}} & r_{x_{4} x_{2}} & r_{x_{4} x_{3}} & 1 & r_{x_{4} x_{5}} \\
r_{x_{5} x_{1}} & r_{x_{5} x_{2}} & r_{x_{5} x_{3}} & r_{x_{5} x_{4}} & 1
\end{array}\right] \\
& =\left[\begin{array}{ccccc}
1 & 0.590 & 0.799 & 0.766 & 0.656 \\
0.590 & 1 & 0.812 & 0.758 & 0.712 \\
0.799 & 0.812 & 1 & 0.874 & 0.798 \\
0.766 & 0.758 & 0.874 & 1 & 0.680 \\
0.656 & 0.712 & 0.798 & 0.680 & 1
\end{array}\right]
\end{aligned}
$$




$$
\begin{aligned}
R_{y_{i} x_{i}} & =\left[\begin{array}{l}
r_{y x_{1}} \\
r_{y x_{2}} \\
r_{y x_{3}} \\
r_{y x_{4}} \\
r_{y x_{5}} \\
\end{array}\right] \\
= & {\left[\begin{array}{l}
0.766 \\
0.818 \\
0.897 \\
0.848 \\
0.801
\end{array}\right] }
\end{aligned}
$$

\section{Mencari Koefisien Jalur}

Menentukan nilai-nilai koefisien jalur diperoleh dari perkalian matriks dengan rumus sebagai berikut:

$$
\left[\begin{array}{l}
\gamma_{y x_{1}} \\
\gamma_{y x_{2}} \\
\gamma_{y x_{3}} \\
\gamma_{y x_{4}} \\
\gamma_{y x_{5}}
\end{array}\right]=\left[\begin{array}{ccccc}
1 & r_{x_{1} x_{2}} & r_{x_{1} x_{3}} & r_{x_{1} x_{4}} & r_{x_{1} x_{5}} \\
r_{x_{2} x_{1}} & 1 & r_{x_{2} x_{3}} & r_{x_{2} x_{4}} & r_{x_{2} x_{5}} \\
r_{x_{3} x_{1}} & r_{x_{3} x_{2}} & 1 & r_{x_{3} x_{4}} & r_{x_{3} x_{5}} \\
r_{x_{4} x_{1}} & r_{x_{4} x_{2}} & r_{x_{4} x_{3}} & 1 & r_{x_{4} x_{5}} \\
r_{x_{5} x_{1}} & r_{x_{5} x_{2}} & r_{x_{5} x_{3}} & r_{x_{5} x_{4}} & 1
\end{array}\right]^{-1}\left[x\left[\begin{array}{c}
r_{y x_{1}} \\
r_{y x_{2}} \\
r_{y x_{3}} \\
r_{y x_{4}} \\
r_{y x_{5}}
\end{array}\right]\right.
$$

Dengan bantuan spss 16.0 diperoleh nilai koefisien jalur yang ditunjukkan pada tabel 4.5 berikut.

Berdasarkan hasil pengelolaan data yang ditunjukkan dalam tabel 4.5 maka didapat nilai koefisien jalur sebagai berikut: 


\section{Koefisien Determinasi $R^{2}$}

Koefisien determinasi digunakan untuk mengukur proporsi atau persentase kemampuan model dalam menerangkan variabel terikat. Koefisien determinasi berkisar antara nol sampai dengan satu $0 \leq R^{2} \leq 1$. Jika $R^{2}$ semakin besar (mendekati satu), maka dapat dikatakan bahwa pengaruh variabel bebas adalah besar terhadap variabel terikat.Hal ini berarti model yang digunakan semakin kuat untuk menerangkan pengaruh variabel bebas terhadap variabel terikat.Menghitung koefisien determinasi $R^{2}$ diperoleh dengan menggunakan rumus:

$$
R^{2}=\left[\begin{array}{lllll}
\gamma_{x_{1}} & \gamma_{y x_{2}} & \gamma_{y x_{3}} & \gamma_{y x_{4}} & \gamma_{y x_{5}}
\end{array}\right] x\left[\begin{array}{c}
r_{y x_{1}} \\
r_{y x_{2}} \\
r_{y x_{3}} \\
r_{y x_{4}} \\
r_{y x_{5}}
\end{array}\right]
$$

Dengan bantuan spss 16.0 diperoleh nilai koefisien determinasi yang ditunjukkan pada tabel 4.6. Berdasarkan tabel 4.6diperoleh bahwa:

1. $R=0.929$ berarti hubungan antara variabel bebas terhadap variabel terikat sangat erat.

2. $\mathrm{R}^{2}=0.863$ berarti $86.3 \%$ prestasi siswa dapat dijelaskan oleh variasi guru mengajar, minat belajar, metode belajar, inteligensi siswa, motivasi belajar, sedangkan sisanya $13.7 \%$ dapat dijelaskan oleh variabel-variabel lain yang tidak termasuk dalam penelitian ini.

3. Standar Error Of Estimated (Standar Deviasi) artinya mengukur variasi dari nilai yang diprediksi. Dalam penelitian ini nilai Standar Error Of Estimated adalah 2.998. Semakin kecil Standar Error Of Estimated berarti model semakin baik. 


\section{Menguji Koefisien Jalur}

Pengujian koefisien jalur untuk menentukan seberapa besar pengaruh variabel bebas terhadap variabel terikat dengan ketentuan sebagai berikut:

$H_{0}: \gamma_{Y X_{1}}=0$, Artinya tidak terdapat pengaruh yang positif dan signifikan dari variabel bebas terhadap variabel terikat.

$H_{1}: \gamma_{Y X_{1}} \neq 0$, Artinya terdapat pengaruh yang positif dan signifikan dari variabel bebas terhadap variabel terikat.

$H_{0}$ diterima jika $t_{\text {hitung }} \leq t_{\text {tabel }} ; \propto=5 \%$

$H_{0}$ ditolak jika $t_{\text {hitung }} \geq t_{\text {tabel }} ; \propto=5 \%$

Hasil pengujiannya adalah:

Tingkat kesalahan $(\propto)=5 \%$ dan derajad kebebasan $(d f)=(n-k)$

$n=$ jumlah sampel, $n=80$

$k=$ jumlah variabel yang digunakan, $k=6$

Maka, derajad bebas $(d f)=n-k=80-6=74$

Nilai $t_{\text {tabel }}$ yang digunakan adalah $t_{0.05(74)}=1.9921$

1. Koefisien jalur $\gamma_{Y X_{1}}$

Berdasarkan tabel 4.5 nilai $t_{\text {hitung }}$ variabel variasi guru mengajar $\left(\mathrm{X}_{1}\right)$ sebesar 2.038 berpengaruh positif dan signifikan sebesar 0.045 . Hipotesis $H_{0}$ ditolak karena $t_{\text {hitung }} \geq t_{\text {tabel }}(2.038 \geq 1.9921)$ yang artinya variabel variasi guru mengajar $\left(\mathrm{X}_{1}\right)$ memberikan pengaruh terhadap prestasi siswa (Y). Jika ditingkatkan satu satuan maka prestasi siswa (Y) akan meningkat sebesar 0.0459 satuan.

2. Koefisien jalur $\gamma_{Y X_{2}}$

Berdasarkan tabel 4.5 nilai $t_{\text {hitung }}$ variabel minat belajar $\left(\mathrm{X}_{2}\right)$ sebesar 2.877 berpengaruh positif dan signifikan sebesar 0.005 . Hipotesis $H_{0}$ ditolak karena $t_{\text {hitung }} \geq t_{\text {tabel }}(2.877 \geq 1.9921)$ yang artinya variabel minat belajar $\left(\mathrm{X}_{2}\right)$ memberikan pengaruh terhadap prestasi siswa (Y). Jika ditingkatkan satu satuan maka prestasi siswa (Y) akan meningkat sebesar 0.8849 satuan.

3. Koefisien jalur $\gamma_{Y X_{3}}$ 
Berdasarkan tabel 4.5 nilai $t_{\text {hitung }}$ variabel metode belajar $\left(\mathrm{X}_{3}\right)$ sebesar 2.125 berpengaruh positif dan signifikan sebesar 0.037 . Hipotesis $H_{0}$ ditolak karena $t_{\text {hitung }} \geq t_{\text {tabel }}(2.125 \geq 1.9921)$ yang artinya variabel metode belajar $\left(\mathrm{X}_{3}\right)$ memberikan pengaruh terhadap prestasi siswa (Y). Jika ditingkatkan satu satuan maka prestasi siswa (Y) akan meningkat sebesar 0.1329 satuan.

4. Koefisien jalur $\gamma_{Y X_{4}}$

Berdasarkan tabel 4.5 nilai $t_{\text {hitung }}$ variabel inteligensi siswa $\left(\mathrm{X}_{4}\right)$ sebesar 2.068 berpengaruh positif dan signifikan sebesar 0.037 . Hipotesis $H_{0}$ ditolak karena $t_{\text {hitung }} \geq t_{\text {tabel }}(2.068 \geq 1.9921)$ yang artinya variabel inteligensi siswa $\left(\mathrm{X}_{4}\right)$ memberikan pengaruh terhadap prestasi siswa (Y). Jika ditingkatkan satu satuan maka prestasi siswa (Y) akan meningkat sebesar 0.0759 satuan.

5. Koefisien jalur $\gamma_{Y X_{5}}$

Berdasarkan tabel 4.5 nilai $t_{\text {hitung }}$ variabel motivasi belajar $\left(X_{5}\right)$ sebesar 2.708 berpengaruh positif dan signifikan sebesar 0.037 . Hipotesis $H_{0}$ ditolak karena $t_{\text {hitung }} \geq t_{\text {tabel }}(2.708 \geq 1.9921)$ yang artinya variabel motivasi belajar $\left(\mathrm{X}_{5}\right)$ memberikan pengaruh terhadap prestasi siswa (Y). Jika ditingkatkan satu satuan maka prestasi siswa (Y) akan meningkat sebesar 0.7159 satuan.

\section{Pembahasan}

Dari hasil penelitian menunjukkan bahwa faktor-faktor belajar yaitu variasi guru mengajar, minat belajar, metode belajar, inteligensi siswa dan motivasi belajar mempengaruhi prestasi siswa. Kesimpulan ini berdasarkan pada tabel 4.6 yang menunjukkan bahwa nilai signifikan $X_{1}(0.045), \quad X_{2}(0.005), \quad X_{3}(0.037)$, $X_{4}(0.042)$ dan $X_{5}(0.008)$ lebih kecil dari $\propto=5 \%$. Koefisien jalur juga menunjukkan pengaruh positif dan signifikan antara variasi guru mengajar $\left(X_{1}\right)$, minat belajar $\left(X_{2}\right)$, metode belajar $\left(X_{3}\right)$, inteligensi siswa $\left(X_{4}\right)$ dan motivasi belajar $\left(X_{5}\right)$ terhadap prestasi siswa $(Y)$, artinya apabila variasi guru mengajar $\left(X_{1}\right)$, minat belajar 
$\left(X_{2}\right)$, metode belajar $\left(X_{3}\right)$, inteligensi siswa $\left(X_{4}\right)$ dan motivasi belajar $\left(X_{5}\right)$ dalam keadaan meningkat maka prestasi siswa $(Y)$ juga akan meningkat, sebaliknya apabila variasi guru mengajar $\left(X_{1}\right)$, minat belajar $\left(X_{2}\right)$, metode belajar $\left(X_{3}\right)$, inteligensi siswa $\left(X_{4}\right)$ dan motivasi belajar $\left(X_{5}\right)$ dalam keadaan menurun maka prestasi siswa $(Y)$ juga akan menurun.

Metode belajar menjadi faktor yang paling berpengaruh, hal ini sesuai dengan pendapat Maiyanti, dkk (2012) bahwa untuk mengetahui besarnya pengaruh ditentukan dengan nilai koefisien jalur, dimana hal ini terlihat pada tabel 4.5 , dimana besar peng metode belajar $\left(X_{3}\right)$ terhadap prestasi siswa $(Y)$ sebesar 0.261 .

\section{KESIMPULAN DAN SARAN}

\section{Kesimpulan}

Berdasarkan hasil analisis jalur yang telah dilakukan, maka peneliti dapat mengambil kesimpulan sebagai berikut:

1. Berdasarkan pembahasan mengenai faktor-faktor yang mempengaruhi belajar terhadap prestasi siswa dengan menggunakan analisis jalur maka diperoleh model persamaan strukturalnya:

$$
Y=0.155 X_{1}+0.226 X_{2}+0.261 X_{3}+0.194 X_{4}+0.199 X_{5}+\varepsilon
$$

Persamaan diatas menunjukkan bahwa pengaruh variasi guru mengajar $\left(X_{1}\right)$ terhadap prestasi siswa $(Y)$ sebesar 0.155 , pengaruh minat belajar $\left(X_{2}\right)$ terhadap prestasi siswa $(Y)$ sebesar 0.226 , pengaruh metode belajar $\left(X_{3}\right)$ terhadap prestasi siswa $(Y)$ sebesar 0.261 , pengaruh inteligensi siswa $\left(X_{4}\right)$ terhadap prestasi siswa $(Y)$ sebesar 0.194 , dan pengaruh motivasi belajar $\left(X_{5}\right)$ terhadap prestasi siswa $(Y)$ sebesar 0.199 .

2. Berdasarkan pengujian koefisien jalur menunjukkan bahwa metode belajar $\left(X_{3}\right)$ merupakan faktor yang paling besar berpengaruh terhadap prestasi siswa $(Y)$, hal ini terlihat pada nilai koefisien jalur yang terdapat pada tabel 4.5 , dimana 
besar pengaruh metode belajar $\left(X_{3}\right)$ terhadap prestasi siswa $(Y)$ sebesar 0.261 . Pada tabel 4.5 juga terlihat bahwa pengaruh positif dan signifikan antara variasi guru mengajar $\left(X_{1}\right)$, minat belajar $\left(X_{2}\right)$, metode belajar $\left(X_{3}\right)$, inteligensi $\operatorname{siswa}\left(X_{4}\right)$ dan motivasi belajar $\left(X_{5}\right)$ terhadap prestasi siswa $(Y)$, artinya apabila variasi guru mengajar $\left(X_{1}\right)$, minat belajar $\left(X_{2}\right)$, metode belajar $\left(X_{3}\right)$, inteligensi siswa $\left(X_{4}\right)$ dan motivasi belajar $\left(X_{5}\right)$ dalam keadaan meningkat maka prestasi siswa $(Y)$ juga akan meningkat, sebaliknya apabila variasi guru mengajar $\left(X_{1}\right)$, minat belajar $\left(X_{2}\right)$, metode belajar $\left(X_{3}\right)$, inteligensi siswa $\left(X_{4}\right)$ dan motivasi belajar $\left(X_{5}\right)$ dalam keadaan menurun maka prestasi siswa $(Y)$ juga akan menurun.

\section{Saran}

Saran-saran yang dapat penulis berikan berdasarkan hasil penelitian ini adalah:

1. Penelitian ini faktor yang digunakan adalah variasi guru mengajar, minat belajar, metode belajar, inteligensi siswa, motivasi belajar. Oleh karena itu, untuk penelitian selanjutnya dapat menambahkan faktor yang lain.

2. Berdasarkan hasil penelitian bahwa faktor belajar yang terdiri dari variasi guru mengajar, minat belajar, metode belajar, inteligensi siswa, motivasi belajar berpengaruh terhadap prestasi siswa. Oleh karena itu, agar prestasi siswa di SMK Negeri 1 Siborongborong dapat menjadi lebih baik, sebaiknya siswa-siswi melakukan perbaikan padametode belajar.

\section{DAFTAR PUSTAKA}

[1] Arikunto, S. (2012).Dasar-dasar Evaluasi Pendidikan. Bumi Aksara: Jakarta.

[2] Dalyono, M. (1997).Psikologi Pendidikan. Rineka Cipta: Jakarta.

[3] Rooijakkers, A. (1990). Mengajar Dengan Sukses. Gramedia: Jakarta.

[4] Robert, Y. K. (1984). Case Tsudy Research Design and Methods. Sage Publication Beverlly: Hills

[5] Riduwan dan Kuncoro, A. E. (2011) .Analisis Jalur. Cetakan ke-4. CV. Alfabeta: Bandung 
[6] Johnson, R. A. dan Wichern.(1992). Applied Multivatiate Staticstical Analysis. Prentice hall: New Jersey. 